\title{
DIE ONTWIKKELING EN TOETSING VAN ARTIKULASIEVERMOËNS BY DIE AFRIKAANSSPREKENDE KIND
}

\author{
ELSIE C. LOTTER, M.A. (LOG.) (PRETORIA) \\ Spraakheelkunde, Universiteit van Pretoria, Pretoria
}

\section{OPSOMMING}

Daar bestaan tans geen gestandaardiseerde Afrikaanse artikulasietoets nie en ontwikkelingsnorms vir die klanke van Afrikaans is nog nie tevore opgestel nie. In hierdie studie is gepoog om 'n stel ouderdomsnorms vir die artikulasievermoë van die Afrikaanssprekende kind daar te stel en om 'n voorlopige vorm van 'n Afrikaanse Artikulasietoets vir gebruik by jong kinders op te stel. Die gegewens van 999 proefpersone (499 seuns en 500 dogters) tussen die ouderdomme 3-9 en 9-6 jaar is verwerk vir die vasstelling van die ontwikkelingsnorms. Die toetsmateriaal vir die artikulasietoets is gekies na aanleiding van die response van 2315 proefpersone. Benewens 'n woordelys vir gebruik as artikulasie-inventaris, word verskeie verwerkings en toepassings van verkreë response voorgestel. Daar word aanbeveel dat die voorlopige toetsformaat die volgende insluit: 'n Tabel vir die optekening van response; gegewens vir die berekening van algemene spraakverstaanbaarheid; materiaal vir die ontlokking van 'n monster van aaneenlopende spraak; 'n metode vir die ontleding van foutresponse; en 'n stimuleerbaarheids-subtoets vir diagnostiese doeleindes.

\section{SUMMARY}

At present, there exists no standardized Afrikaans articulation test and developmental norms for the sounds of Afrikaans have not yet been established. This study attempts to provide a set of age norms for the articulatory abilities of Afrikaans-speaking children and to formulate a preliminary Afrikaans Articulation Test to be used with young children. Data collected from 999 subjects, ( 499 boys and 500 girls) between the ages 3-9 and 9-6 years, were processed for the establishment of the developmental norms. The material used for the articulation test was selected according to responses obtained from 2315 subjects. In addition to a list of words to be used as an articulation inventory, several computations and applications of responses obtained from subjects are proposed. It is suggested that the preliminary test format include the following: an index for the recording of responses; data for the computation of general speech intelligibility; material for eliciting a sample of continuous speech; a method for the analysis of error responses; and a stimulability subtest for diagnostic purposes.

Die studie en behand eling van artikulasieprobleme word dikwels as 'n betreklik eenvoudige onderafdeling van die spraakpatologie beskou. Ten spyte hiervan vind baie terapeute tog dat die meeste van hulle tyd deur gevalle met artikulasieprobleme in beslag geneem word, dikwels ten koste van kinders wat blykbaar ernstiger probleme het en hulp meer nodig het. Stewart ${ }^{9}$ wys egter daarop dat die tyd wat nodig is om bevredigende spraak by sommige van hierdie kinders te verkry, skynbaar buite alle verhouding is met die opgawe soos hy hom by die eerste oogopslag voordoen. 
Navorsers besef in ' $n$ toenemende mate dat Powers' se uitgangspunt aandag verdien: artikulasieprobleme is geensins so eenvoudig om te verklaar en te behandel as wat baie mense aanvaar nie. Die instrumente waarmee die terapeut artikulasievermoëns kan ondersoek en 'n sinvolle terapieprogram opstel, neem dus ' $n$ belangrike plek in.

'n Artikulasie-inventaris bied 'n stelselmatige wyse waarop die klanke wat in die betrokke taal as foneemrealiserings benodig word, nagegaan kan word. 'n Gesistematiseerde oorsig van die pasiënt se produksie van hierdie klanke vergemaklik die beplanning van die terapieprogram.

Soms is dit ook nodig, veral by baie jong kinders, om na te gaan watter klankproduksies wel al bemeester moes gewees het en of daar sommige ,klankfoute' voorkom wat op daardie ouderdom nog as normaal beskou word. Hierdie oorwegings dra ook by tot die opstel van realistiese terapiedoelstellings. Ontwikkelingsnorms (ouderdomsnorms) lê dus dikwels ten grondslag van die sinvolle interpretasie van 'n persoon se prestasie tydens 'n artikulasietoets.

Ouderdomsnorms word benut in verskillende soorte artikulasietoetse siftingstoetse, diagnostiese en voorspellingstoetse.

'n Stelselmatige aanduiding van artikulasievermoëns is egter nie net in terapie nut tig nie, maar ook vir navorsingsdoeleindes. Nie slegs op die gebied van artikulasieafwykings as sodanig nie, maar ook by studies waar die klem op ander oorwegings val, word die artikulasietoets dikwels gebruik. Voorbeelde van sulke studies word oral in die huidige vakliteratuur aangetref. In baie van hierdie gevalle word prestasie op die artikulasietoets juis in terme van ontwikkelingsnorms geinterpreteer.

Daar kan dus geen twyfel bestaan dat die artikulasietoets of -inventaris, met sy gegewens in verband met ontwikkelingspeile, wel 'n belangrike instrument vir die klinikus en die navorser is nie.

Wat die ontwikkeling en afwykings van spraak en taal betref, is daar betreklik min navorsing in Afrikaans en oor Afrikaans gedoen. Waar dit wel aangevoer is, is meestal ongestandaardiseerde vertalings en/of aanpassings van Engelse en Amerikaanse toetse gebruik. Die gebruik van sodanige vreemde toetse lewer egter nie werklik geldige of betroubare resultate nie, veral nie met betrekking tot artikulasie nie. Elke taal het 'n verskillende foneemstelsel en selfs 'n verskillende artikulasiebasis. Waar baie navorsingsprogramme tans ger ig is op veral die ontwikkeling van die taalstelsel as geheel en die verband tussen die onderafdelings van taal (wat ook die foneemstelsel en die realisering daarvan insluit) is daar ' $n$ dringende behoefte aan basiese inligting. Hierdie inligting moet, vir Afrikaans, nog ingesamel word.

In hierdie studie word dan gepoog on:

(i) Sekere basiese gegewens in verband met artikulasieontwikkeling te voorsien, as grondslag vir verdere navorsing; dit wil sê, om ontwikkelingsnorms vir artikulasievermoë by die jong Afrikaanssprekende kind vas te stel.

(ii) 'n Instrument daar te stel waarmee sodanige basiese gegewens by ander individuele en groepe proefpersone ingesamel'kan word, hetsy vir terapeutiese of navorsingsdoeleindes; dit wil sê, om 'n voorlopige vorm van 'n Afrikaanse artikulasietoets vir gebruik by jong kinders op te stel. 
1

Die navorsing wat onderneem is, het dus ook twee sake behels. In die eerste plek, die toetsing van die klanke wat as foneemrealiserings in Afrikaans voorkom, soos dit deur 'n groot groep kinders van verskillende ouderdomme geproduseer word. In die tweede plek, die versameling van 'n lys woorde wat geskik sal wees vir gebruik in 'n artikulasietoets by kinders van verskillende ouderdomme.

Hierdie twee aspekte is tydens dié ondersoek gelyktydig gedek.

\section{METODE}

\section{PROEFPER SONE}

Proefpersone vir hierdie studie moes ,jong Afrikaanssprekende kinders" wees. Kinders vanaf die ouderdom 3-9 tot $9-6$ is in die ondersoek ingesluit. (Navorsingsgegewens uit Amerikaans, Engels en Duits dui daarop dat kinders teen ongeveer 8 jaar reeds al die klanke van hulle taal behoort te kan sê. Die hipotese kan dus gestel word dat dit ook vir Afrikaans die geval sal wees).

Alle proefpersone is uit Afrikaanse skole of kleuterskole getrek. Die vereiste van Afrikaans as huistaal is ook gestel.

Kinders met sigbare fisiese afwykings, gehoorverlies of neurologiese afwykings (waar bekend) is nie in die ondersoek opgeneem nie. Die ontwikkelingsnorms sal dus geld vir kinders met normale fisiese strukture.

'n Totaal van 999 proefpersone (500 dogters, 499 seuns) is gebruik om die ontwikkelingsnorms te bepaal. Die gegewens van 2315 kinders is gebruik om die bekendheid van die woorde of prente wat as toetsmateriaal gebruik is, te bepaal.

\section{TOETSMATERIAAL}

Die toetsmateriaal moes 'n middel voorsien waardeur die ondersoeker 'n verteenwoordigende monster van elke proefpersoon se spraak kon ontlok. Hierdie spraakmonster moes aan sekere vereistes voldoen: dit moes spontaan wees, dit moes verteenwoordigend wees en die verkryging daarvan moes nie te veel tyd in beslag neem nie. Uit hierdie vereistes het geblyk dat die toetsmateriaal woorde moes behels wat deur middel van prentstimulasie by jong kinders ontlok kon word en waar in die verlangde klanke dan in die verlangde posisies in woorde (prevokalies, intervokalies, postvokalies) sou voorkom. Slegs konsonantklanke (enkelklanke en klankkombinasies) is in hierdie studie gedek; - vokaalklanke is nie ondersoek nie.

Aangesien dit belangrik was dat kinders goed moes reageer op die prentstimulasie, moes die mees doeltreffende soort prente gebruik word. Shanks, Sharpe \& Jackson ${ }^{8}$ vergelyk verskillende soorte prente en bevind dat kinders die beste op gekleurde foto's reageer. Die onkoste hieraan verbonde sou egter onprakties wees vir 'n ondersoek van hierdie aard. Groot gekleurde tekeninge is dus gebruik waarop voorwerpe so realisties as moontlik uitgebeeld is.

By die aanvang van toetsing is 'n voorlopige woordelys en prente saamgestel. Tydens die verloop van die ondersoek is hierdie materiaal na behoefte gewysig. As dit geblyk het dat 'n betrokke woord of prent by meer as $50 \%$ van die proefpersone wat op een dag ondersoek is, onbekend was, is dit vervang. 
Die finale woordelys is aangedui in Tabel 1.

\begin{tabular}{|c|c|c|c|c|c|}
\hline Woord & $\mathscr{\%}$ & Woord & $\mathscr{B}$ & Woord & $g$ \\
\hline 1. hare & 0,0 & 21. brood & $.1,2$ & 41. piesang & 6,3 \\
\hline 2. broek & 0,0 & 22. blare & 1,3 & 42. vliegtuig & 7,7 \\
\hline 3. knoop & 0,1 & 23. wiel & 1,6 & 43. boks & 7,9 \\
\hline 4. drink & 0,1 & 24. seuntjie & 1,9 & 44. wolke & 8,7 \\
\hline 5. sleutels & 0,1 & 25. stoof & 2,0 & 45.spieël & 8,8 \\
\hline 6. skoene & 0,1 & 26. mielie & 2,0 & 46. glas & 9,3 \\
\hline 7. mes & 0,1 & 27. stryk & 2,7 & . 47. pleister & 9,7 \\
\hline 8. neus & 0,2 & 28. kar & 2,8 & 48. kwas & 10,0 \\
\hline 9. lepel & 0,2 & 29. tafel & 2,8 & 49. vloer & 11,6 \\
\hline 10. huis & 0.2 & 30. water & 2,9 & 50. skryf & 12,3 \\
\hline 11. vurk & 0,2 & 31. emner & 3,5 & 51. spring & 15,4 \\
\hline 12. druiwe & 0,3 & 32. masjien & 3,5 & 52. jas & 15,9 \\
\hline 13. boom & 0,3 & 33. deur & 3,5 & 53. kraan & 18,8 \\
\hline 14. perd & 0,4 & 34. geld & 3,7 & 54. lamp & 20,4 \\
\hline 15. olifant & 0,7 & 35. voël & 3,8 & 55. prop & 23,6 \\
\hline 16. swem & 0,8 & 36. fiets & 4,1 & 56. zebra & 31,8 \\
\hline 17. vingers & 0,8 & 37. gras & 4,6 & 57. skulp & 32,8 \\
\hline 18. rok & 1,0 & 38. klippe & 4,7 & 58. gholf & 42,1 \\
\hline 19. seep & 1,0 & 39. berg & 5,2 & 59. gogga & 45,9 \\
\hline \multirow[t]{2}{*}{ 20. trein } & 1,1 & 40. baba & 5,8 & 60. beker & 60,9 \\
\hline & & & & 61. sjokolade & 62,1 \\
\hline
\end{tabular}

TABEL 1. Finale woordelys by ondersoek na artikulasievaardighede, tesame met persentasie foutiewe response verkry.

\section{AI,GEMENE PROSEDURE}

Die toetsmateriaal (woorde) is aangewend om 'n sprakvoorbeeld van elke proefpersoon te verkry. Hierdie voorbeeld is dan deur die ondersoeker perseptueel ontleed om die resultate vir die ontwikkelingsnorms te verkry.

Die groot, gekleurde tekeninge is aangebied vir elke proefpersoon, met toepaslike vrae waar nodig ten einde die verlangde respons te ontlok. (Die verlangde woord is nooit in die vraag gebruik nie).

Die respons van elke proefpersoon op elke prent is aangeteken, vir sowel bepaling van die bekendheid van prente, as beoordeling van artikulasievermoë. 
'n Getroue fonetiese transkripsie is vir die optekening gebruik. Die getranskribeerde response is dan geklassifiseer as aanvaarbaar/nie aanvaarbaar nie, volgens die volwasse standaardpatroon.

\section{RESULTATE: OUDERDOMSNORMS}

Die gegewens van 999 proefpersone is verwerk en in tabelvorm uiteengesit. 'n Getroue weergawe is ontwikkel deur IBM 360 Model 50 Komper, met die program „Interest" en ook verdere programme wat deur die personeel van die Rekenaarsentrum aan die Universiteit van Pretoria opgestel is. Die tabelle word nie hier weergegee nie omdat hulle te lywig is. Die volgende is 'n samevatting van die vernaamste bevindings:

(a) Hoewel die persentasie proefpersone wat die konsonantklanke (enkelklanke en klankkombinasies) korrek produseer, in sommige gevalle met toename in ouderdom 'n stygende neiging toón, was daar vir geen klank 'n deurlopende styging nie. Afnames in die persentasie proefpersone wat 'n korrekte produksie lewer, kom voor in die omgewing van 5-0 tot 5-8, 6-8 tot 7-6 en weer voor 8.8. Indien hierdie ondersoek met ander proefpersone en ander toetsmateriaal herhaal sou word en dieselfde resultate oplewer, sal 'n verklaring moontlik gesoek moet word in die verband tussen die ontwikkeling van artikulasievermoë en ander vermoëns. 'n Voorlopige hipotese kan gestel word in terme van tydperke van intensiewe konseptuele ontwikkeling, waartydens dan minder aandag aan die korrekte realisering van foneme (wat tog op 'n vroeëre ouderdom reeds bemeester is) geskenk word.

(b) Enkelklanke word oor die algemeen vroeër as klankkombinasies bemeester, met die uitsondering van die enkelklanke $[\mathrm{r}]$ en $[\mathrm{s}]$. Op die ouderdom van 8 jaar produseer die meeste kinders (75\%. 90\%) al die konsonantklanke van Afrikaans korrek, met uitsondering van die klankkombinasie [-rs]. 'n Steekproef met 50 volwasse proef persone het getoon dat $26 \%$ van die volwassenes ook 'n foutiewe produksie van dié klankkom. binasie lewer. Die vorms wat gewoonlik voorkom, naamlik $[4 \mathrm{~s}]$ of $[\mathrm{r} f]$, word egter algemeen as aanvaarbare variante beskou.

(c) Soos weerspieël deur die persentasie fouteerders, blyk dit dat [s, r, $f$, $\mathrm{z}, \mathrm{g}]$, in daard ie volgorde, die vyf moeilikste enkelkonsonantklanke vir kinders binne die ouderdomsgroep 3-9 tot 9-6 was. As hierdie gegewens met dié vir Amerikaans, Engels en Duits vergelyk word, is daar 'n groot mate van ooreenstemming, veral ten opsigte van $[s, z, \delta]$. Dit blyk dat die sibilante klanḱe in al vier hierdie tale as moeilik produseerbare klanke ondervind word.

(d) Wat die moeilikheidswaarde van konsonantklankkombinasies betref, is [-rs] die moeilikste. Al tien die moeilikste konsonantklankkombinasies bevat $[r],[s]$ of albei as komponent.

(e) Dit lyk asof die enkelkonsonantklanke moeiliker produseerbaar is in die eind- as in die aanvangsposisie in woorde. 'n Verklaring hiervoor kan gevind word in die hipotese van McDonald, ${ }^{5}$ dat die eindkonsonant van 
'n lettergreep, as gevolg van die tydsfaktor, in aaneenlopende spraak na die begin van die volgende lettergreep verskuif. Die eindkonsonante is gevolglik moontlik minder konstant en moeiliker om aan te leer.

(f) Wanneer konsonante ten opsigte van manier van vorming met mekaar vergelyk word, kom die grootste persentasie fouteerders' op wrywingsklanke voor. Die konsonantsoorte kan in volgorde van die grootste na die kleinste persentasie fouteerders só gerangskik word: wrywingsklanke, die ratel- of tikklank, die wrywinglose kont inuant met laterale lugvrylating, afslujitingsklanke, wrywinglose kontinuante met nasale lugvrylating. Hierdie bevindings stem ooreen met dié van Templin ${ }^{10}$ vir Amerikaans.

Die ontwikkelingsnorms wat in hierdie ondersoek vasgestel is, is nuttig vir gebruik in verdere navorsing en ook by die opstel van 'n voorlopige vorm van 'n Afrikaanse artikulasietoets.

\section{BESPREKING : VOORLOPIGE VORM VAN 'N ARTIKULASIETOETS}

By 'n beoordeling van die toetsformat wat hier voorgestel word, moet die voorwaardes wat deur Goldman \& Fristoe ${ }^{3}$ gestel is, veral in gedagte gehou word: 'n Artikulasie-inventaris of -toets is slegs doeltreffend as dit akkurate en voldoende inligting oplewer, as dit binne 'n kort tyd toegepas kan word en as dit vir die kind 'n hoë interessantheidswaarde het. Die toets moet dus materiaal bevat wat aan die kinders bekend is en wat hulle aandag sal behou, maar terselfdertyd noet die ondersoeker die materiaal en die verwerking van die resultate maklik kan hanteer.

\section{TOETSMATERIAAL}

Die toetsmateriaal sal bestaan uit prente wat so gekies is, dat die kind in die benoeming van die hele stel prente, dje enkelkonsonantklankè en konsonantklankkombinasies van Afrikaans sal produseer. Enkelklanke word in drie posisies in woorde (te wete aanvang, middel en end) ontlok, behalwe in gevalle waar die taalreëls spesifiseer dat 'n klank nie in 'n bepaalde woordposisie voorkom nie. Die klankkombinasies word elk net in een woordposisie ont lok, na gelang van die aard van die bepaalde klankkombinasie. Om die lengte van die toets te beperk, word in sommige gevalle meer as een klank per woord beoordeel.

Die woordelys wat in Tabel 1 aangegee is, kan gebruik word as 'n bron vir die woorde wat in die artikulasie-inventaris opgeneem word.

Die 54 woorde wat in Tabel 11 verskyn word aanbeveel.

Daar word aanbeveel dat verdere ondersoek ingestel word om meer doeltreffende stimuluswoorde vir die volgende gevalle te vind:

$[\mathrm{k}],[\mathrm{x}]$ en $[\mathrm{d}]$ in middelposisie van woorde.

Daar moet ook verder gepoog word om woorde te vind wat die klanke wat nie by hierdic toets ingesluit is nie, te ontlok. Sekere klankkombinasies, bv. [spl-, -rf, -rps], moes weggelaat word. Hierdie klankkombinasies kon moeilik deur middel van prente ontlok word omdat dit nie voorkom in woorde wat aan kinders bekend is, of wat met 'n prent voorgestel kan word en 'n bevredigende respons lewer niè. 


\begin{tabular}{|c|c|c|c|c|}
\hline 1. perd & & 19. olifant & & 37. glas \\
\hline 2. lepel & & 20. spieël & & 38. prop \\
\hline 3. seep & & 21. rok & & 39. drink \\
\hline 4. boom & & 22. hare & & 40. kraan \\
\hline 5. baba & & 23. piesang & - & 41. gras \\
\hline 6. mes & & 24. kat & & 42. swem \\
\hline 7. emmer & & 25. beker & & 43. kwas \\
\hline 8. vurk & & 26. geld & & 44. knoop \\
\hline 9. tafel & & 27. vliegtuig & & 45. spring \\
\hline 10. stoof & & 28. gholf & & 46. stryk \\
\hline 11. water & & 29. masjien & & 47. skryf \\
\hline 12. drujwe & & 30. vingers & & 48. skulp \\
\hline 13. brood & & 31 . jas & & 49. wolke \\
\hline 14. deur & & 32. pleister & & 50. berg \\
\hline 15. sjokolade & & 33. zebra & & 51. fiets \\
\hline 16. neus & & 34. blare & $\cdot$ & 52. boks \\
\hline 17. skoene & & 35. sleutels & & 53. seuntjie \\
\hline 18. trein & & 36. klippe & & 54. lamp \\
\hline
\end{tabular}

TABEL II. Aanbévole woordlys vir artikulasieinventaris.

Die onderstreepte gedeeltes van die woorde in die aanbevole lys, dui op die klanke wat tydens produksie van die bepaalde woord geëvalueer word. Daar word egter aanbeveel dat die ondersoeker ook op elkéander realisering van die betrokke klank wat in die res van die toets mag voorkom, sal let.

\section{OPTEKENING VAN RESPONSE}

Daar word aanbeveel dat elke uiting van die toetsling so getrou as moontlik foneties getranskribeer word, met bykomstige aantekeninge en/of diakritiese tekens waar nodig. Sodoende word die grootste moontlike hoeveelhejd inligting vir verdere interpretasie voorsien.

'n Tabel soos die wat deur Goldman \& Fristoe ${ }^{3}$ voorsien word, kan dien om . 'n stelselmatige oorsig van die toetsling se response op die artikulasieinventaris te gee. In hierdie tabel is die klanke volgens ontwikkelingsvolgorde (soos uit hierdie navorsing verkry is) gerangskik. Die ouderdomsnorms kan by die. toetsformaat ingesluit word, sodat die response van die toetsling daarmee vergelyk kan word. 


\section{BYKOMSTIGE VERWERKING VAN GEGEWENS}

$\mathrm{Na}$ 'n noukeurige bestudering van die massa literatuur wat reeds oor die onderwerp artikulasietoetsing verskyn het, is 'n paar aanbevelings vir die bykomstige verwerking van gegewens uitgelig.

Die volgende het geblyk die mees belowende en nuttige moontlikhede te wees:

(a) Artikulasievaardigheid in aaneenlopende spraak: Die belang van 'n indruk van die toetsling se artikulasievaardigheid in aaneenlopende spraak, word allerweë beklemtoon. Twee maatstawwe kan hier gebruik word:

(i) 'n Numeriese punt as aanduiding van algemene spraakverstaanbaarheid, soos aanbeveel deur Barker ${ }^{1}$ en Barker \& England. ${ }^{2}$ Hierdie. punt word gegrond op die voorkomsfrekwensie van klanke; as die kind 'n aantal klanke met hoë voorkomsfrekwensie foutief produseer, sal dit sy spraak meer onverstaanbaar mak as wanneer hy 'n aantal klanke met lae voorkomsfrekwensie foutief sou produseer. Die gegewens van Odenda $1^{6}$ kan gebruik word om so 'n puntetoekenning vir die klanke van $A$ frikaans te bereken.

(ii) Om 'n perseptucle indruk van die toetsling se aaneenlopende spraak te verkry, kan 'n verhalende toets soos die van Goldman \& Fristoe $^{3}$ opgestel word. Die enkelklanke en klankkombinasies wat vir die totale groep kinders in die huidige ondersoek die moeilikste was, kan in so 'n verhalende toets ingesluit word. 'n Stel sinne, waarby toepaslike prente gebruik kan word, is ook reeds opgestel; die praktiese toepasbaarheid daarvan moet egter nog deur verdere navorsing vasgestel word.

\begin{tabular}{|lccc|}
\hline \multicolumn{1}{|c}{ Eienskappe } & $\Psi$ & $\theta$ & $\mathrm{S}$ \\
Medio-alveolêr & $\checkmark$ & $\mathrm{x}$ & $\checkmark$ \\
Bladlinguaal & $\checkmark$ & $\mathrm{v}$ & $\checkmark$ \\
Medio-orale lugvrylating & $\mathrm{x}$ & $\checkmark$ & $\checkmark$ \\
Stemloos & $\checkmark$ & $\checkmark$ & $\checkmark$ \\
Frikatief & $\checkmark$ & $\checkmark$ & $\checkmark$ \\
\hline Eienskappe teenwoordig & 4 & 3 & 5 \\
\hline
\end{tabular}

TABEL III. Fonetiese eienskappevan $[s],[\theta]$ en [ $q$ ]

(b) Aard van foute: Die artikulatoriese kenmerke van elke klank, enkelklanke sowel as klankkombinasies, kan by die toetsvorm ingesluit word. Die artikulatoriese kenmerke van die toetsling se foutklanke kan dan met die 
standaardpatroon vergelyk word, soos voorgestel deur Hutcheson. ${ }^{4}$ Uit so. 'n ontleding kan afleidings gemaak word in verband met besondere gebiede van uitval, byvoorbeeld verskille tussen die realisering van 'n foneem in verskillende woordposisies, patroon van gebruik van sekere artikulatoriese eienskappe, en so meer. Tabel III is 'n voorbeeld van die vergelyking van die fonetiese (artikulatoriese) eienskappe van [s] met die foutiewe realiserings $[\theta]$ en $[$ ]

(c) 'Stimulecrbaarheid as diagnosticse matstaf: Winitz ${ }^{11}$ berig dat artikulasieverbetering met die grootste mate van betroubaratheid voorspel kan word op grond van reaksie op stimulasie met die korrekte klankpatroon en die toetsling se telling op die aanvanklike artikulasietoets. 'n Stimuleerbaarheidssubtoets, soortgelyk aan dić wat deur Goldman \& Fristoe ${ }^{3}$ aangegee word, kan dus by die Afrikaanse artikulasietoets ingesluit word.

Wanneer die Afrikaanse Artikulasietocts in sy finale vorm opgestel word, sal die resultate uil die navorsing soos hierbo uitecngesit, hopelik nuttig gebruik kan word. As hierdie studie kan dien om verdere navorsing ten opsigte van dic breè taalspektrum van $\Lambda$ frikaans te stimuleer, het dit in sy doel geslaag.

\section{ERKENNING}

Hierdie navorsing is moont lik gemaak deur die geldelike steun van die Raad vir Geesteswetenskaplike Navorsing. Enige menings wat uitgespreek word, is egter uitsluitlik dié van die skryfster.

\section{VERWYSINGS}

1. Barker, J. (1960): A numerical measure of articulation. J. Speech \& Hearing Dis., 25, 79-88.

2. Barker, J., \& England, G. (1962): A numerical measure of articulation: Further developments. J. Speech \& Hearing Dis., 27, 23-27.

3. Goldman, R. \& Fristoe, M. (1969): Goldman-Fristoe Test of Articulation. American Guidance Service, Inc., Minnesota.

4. Hutcheson, S. (1968): Some quantitative and qualitative criteria in articulation test scoring. Brit. J. Dis. Commun., 3, 36-42.

5. McDonald, E.T. (1969): Articulation Testing and Treatment. A SensoryMotor Approach. Stanwix House lnc., Pittsburgh.

6. Odendal, F.F. (1962): Die Struktuur van die Afrikaanse Wortelmorfeem. H.A.U.M., Kaapstad en Pretoria.

7. Powers, M.H. (1957): Functional Disorders of Articulation. Chapt. 23, in Handbook of Speech Pathology, Appleton-Century-Crofts, New York.

8. Shanks, S.J., Sharpe, M.R. \& Jackson, B.R. (1970): Spontaneous, responses of first grade children to diagnostic picture articulation tests. $J$. Commun. Dis., 3, 106-117. 
9. Stewart, A. (1968): Disorders of articulation in children. Brit. J. Dis. Commun., 3, 121-129.

10. Templin, M.C. (1957): Certain Language Skills in Children. University of Minnesota Press, Minneapolis.

11. Travis, L.E. (Ed.). (1957): Handbook of Speech Pathology. AppletonCentury-Crofts, New York.

12. Winitz, H. (1969): Articulatory Acquisition and Behavior. AppletonCentury-Crofts, New York.

\title{
FOR ALL YOUR MEDICAL BOOK AND JOURNAL REQUIREMENTS
}

\author{
CONSULT \\ THE SPECIALISTS \\ P. B. MAYER \\ 902 Norwich House \\ Heerengracht \\ CAPE TOWN \\ Telephone 2-9231
}




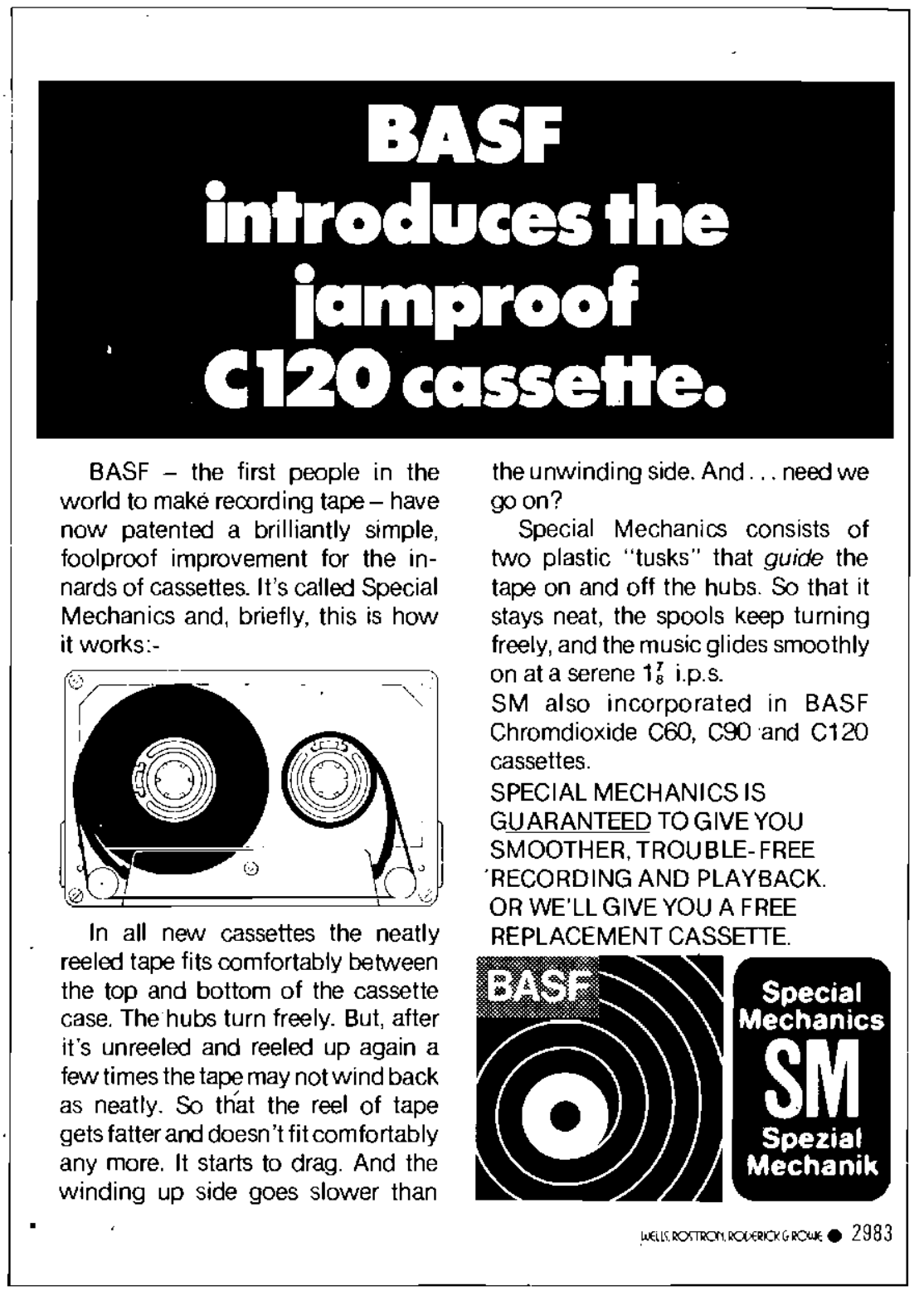




\section{Philips Hearing Aid Services}

A Division of S.A. Philips (Pty) Ltd.

\section{hearing aids \\ portable \\ audiometers}

\section{group teach
systems}

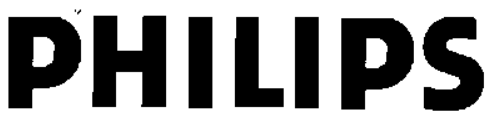

HEARING AID SERVICES

Head Office 1005 Cavendish Chambers, 183 Jeppe Street, P.O. Box 3069, JOHANNESBURG.

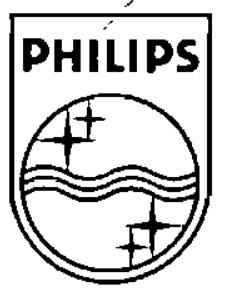

